\title{
Bibliometric Review of the Knowledge Base on Healthcare Management for Sustainability, 1994-2018
}

\author{
Prattana Punnakitikashem ${ }^{1, *}$ and Philip Hallinger ${ }^{1,2}$ (i) \\ 1 Center for Research on Sustainable Leadership, College of Management, Mahidol University, 69 Vipavadee \\ Rangsit Rd., Bangkok 10400, Thailand; Philip.hal@mahidol.ac.th \\ 2 Department of Educational Leadership and Management, University of Johannesburg, \\ Johannesburg 2006, South Africa \\ * Correspondence: prattana.pun@mahidol.ac.th
}

Received: 5 December 2019; Accepted: 20 December 2019; Published: 25 December 2019

\begin{abstract}
In response to the United Nations' (UN) Sustainable Development Goals (SDGs), health care organizations throughout the world have adopted management initiatives designed to increase their sustainability. This review of research used bibliometric methods to analyze a dataset comprised of 477 documents extracted from the Scopus database. The review sought to document research on sustainable healthcare management (SHM) that has accumulated over the past 25 years. Results indicated that the intellectual structure of this body of knowledge is comprised of three schools of thought: (1) sustainable change in health care services, (2) innovations in managing health care operations, and (3) prioritizing and allocating resources for sustainability. The review also highlighted the recent topical focus of research in this literature. Key topics were linked to organization and management of health care services, quality of patient care, and sustainability of health care delivery.
\end{abstract}

Keywords: healthcare management; healthcare; organization; sustainability; corporate sustainability; science mapping; bibliometric review

\section{Introduction}

The health status of a country's population defines its development in terms of the well-being and quality of life of its citizens [1]. Consequently, throughout the world, higher levels of sustainable health care have been demanded by citizens from governments [2]. Rising costs and increased public awareness of health and wellness issues has placed health care management under increased scrutiny. In response, health care organizations have striven to improve the quality of patient safety and care, and increase both the efficiency and accessibility of health care services [3,4].

Publication of the Millennium Development Goals by the United Nations (UN) served as impetus for scholars, policymakers and health care practitioners to act more intentionally and forcefully to develop sustainable health care services and systems [5]. For example, the Green Guide for Health Care [6] provided guidelines not only for the delivery of health care services, but also for the design, construction and operation of health care facilities.

Subsequent publication of Global Sustainable Development Goals (SDGs) by the UN in 2015 provided further momentum for the move towards sustainable health care [7]. More specifically, SDG \#1 targets improved food security and nutrition for people in all nations. SDG \#3 emphasizes the common goal of developing the capacity for people to lead healthy lives and achieve well-being at all ages. SDG \#6 addresses the need for all people to have access to clean water and sanitation. SDG \#11 seeks to ensure that all human settlements remain inclusive, safe, resilient, and sustainable. These SDGs, each of which focuses on an aspect of sustainable health care, are part of the 2030 Agenda for Sustainable Development, adopted by all UN Member States in 2015 [8]. 
Although the term 'sustainability' is relatively new in health care research, it is becoming a topic of growing interest [3]. As suggested above, the ability of societies and institutions to achieve the sustainable development goals will depend, to no small degree, on the adoption of new and more 'sustainable' methods of managing health care services, organizations, and systems. For example, some advocates have suggested that sustainable health care will be achieved through reorientation of health care organizations around the 'triple bottom line' of social, environmental, and economic outcomes $[5,9,10]$. It is noted that in this review of research, the term 'healthcare management for sustainability' and 'sustainable healthcare management' are used interchangeably. Until recently, there have been a small number of systematic review papers on relevant health care disciplines and sustainability in the literature [11-13]. However, reviews that focus explicitly on sustainable healthcare management remain limited.

The purpose of this paper is to review research in the field of healthcare management for sustainability using science mapping review methodology. The review addresses the following research questions $(\mathrm{RQ})$ :

- RQ1: What are key growth trends in research on healthcare management for sustainability?

- RQ2: What authors and documents in the literature on sustainable healthcare management have had the greatest impact on citations over the past 25 years?

- RQ3: What is the intellectual structure of the knowledge base on sustainable healthcare management?

- RQ4: What topics in the sustainable healthcare management literature have been studied with the greatest frequency and are currently attracting the greatest attention?

This review of research provides a systematic examination of the body of research conducted on healthcare management for sustainability knowledge base [14-17]. The review used bibliometric methods to analyze a dataset comprised of 477 Scopus-indexed documents. Descriptive statistics were used to document trends in the growth and composition of sustainable healthcare management (SHM) literature. Citation, co-citation, and keyword co-occurrence analysis were conducted in order to surface authorship, document and topical trends.

The review updates and extends findings from past reviews of sustainability in healthcare. Prior efforts that used other review methods, and focused on more narrow dimensions, such as facility development [17] and waste management $[18,19]$. This is the first effort aimed at 'science mapping' the full literature in this domain of sustainability.

\section{Background Literature}

The promotion of sustainability can be viewed from organizational, community, and system levels $[13,18]$. Proctor et al. [20] used cluster mapping to explore challenges in sustainability research and provided recommendations that supported the move towards evidence-based health care. Later literature broadened the scope of sustainability research in healthcare management [21-23]. More specifically, scholars and management practitioners identified the salience of 'business transformation strategies' focusing on operational process improvement for increasing the efficiency and sustainability of health care organizations [21,24]. These strategies included the Lean/Toyota Production System, Six Sigma, and total quality management [21], all of which aim to foster improvement in organizational processes and performance outcomes. Despite this trend in healthcare management practice, evidence of sustained results from continuous improvement programs remains limited [22]. Moreover, this line of research can be considered to be most closely aligned with the 'economic' perspective on sustainability, as opposed to environmental or social perspectives.

Another line of research and practice in sustainable health care management has focused on enabling organizational change in a dynamic health care environment. This application of management theory and practice has examined how vision, mission, and strategy of the organization can be reoriented to support a sustainability agenda. Some efforts to 're-vision' health care organizations 
around a sustainability agenda have centered on adoption of a triple bottom line $[5,9,10,25]$. Programs adopting this approach have emphasized the need to engage health care stakeholders in setting and achieving sustainability goals that encompass social, environmental and economic dimensions [9]. Within this 'change management perspective', scholars and health care managers have frequently employed the conceptual model of diffusion, dissemination, and implementation of innovations as a means of strengthening the innovative capacity of health service organization [11].

Sustainability has also been incorporated into health care management by paying greater attention to the integration of management processes and the architecture and design of health care facilities [26]. Architectural design elements that foster sustainability include (1) ambient conditions (e.g., spatial layout and functionality); (2) signs, symbols, and artefacts; (3) materials; and (4) technical systems. Organizational and management factors that bear on social and environmental sustainability of health care organizations include organizational culture, structures and roles, human resource practices, leadership, and work processes [26,27]. Sheth et al. [17] reviewed health facilities design in the contexts of new guidelines: Leadership in Energy and Environmental Design (LEED), and the Green Guide to Health Construction (GGHC). Solving problems of energy consumption and waste management was linked to the redesign of healthcare facilities [17]. The urgent need for improvements in healthcare waste management was highlighted, along with selective innovations in operations management [17-19].

Most recently, recognition of the interconnectedness of sustainability challenges has led to a greater focus on how the 'macro-level' health care system shapes sustainability at the community and organizational levels [28]. For example, 'disinvestment' became a topic of interest due to policy efforts undertaken by the National Health Service (NHS) in the United Kingdom. Five types of disinvestment have been identified and studied: investment in savings, substitution, contractual variation, restriction, and full withdrawal [29].

Given the use of bibliometric review methods in the current paper, the authors also wish to acknowledge past bibliometric reviews in this field [30-33]. For example, bibliometric reviews have been published on performance measurement in health care [30], multi-criteria decision making in health care [33], and health care risk management [31]. However, no prior reviews have examined the health care in management literature from the broader perspective of sustainability. This gap in the literature frames the current bibliometric review.

\section{Methodology}

In this section of the paper, the authors present the procedures used in selecting documents for reviewing and analyzing the data.

\subsection{Identifying Sources for the Review}

The Scopus index was selected as the data repository from which to search for and extract documents. Empirical comparisons have found that Scopus offers more comprehensive coverage of sources than the Web of Science for fields outside of medicine and the physical sciences [34]. While it may be argued that the more limited coverage of the Web of Science generates a database comprised of higher quality sources, the authors contend that this is in fact a field-specific question that is subject to empirical verification [35]. Lacking such information for research on the inter-disciplinary field of sustainable healthcare management, we referred to a prior study conducted by Archambault and colleagues (2009). They found that the articles and citations sourced from the Web of Science and Scopus were highly correlated [36]. With this in mind, we opted for the broader coverage offered by Scopus [14,37].

The review is bounded by the first document identified by the authors, which was published in 1994, up until the end of 2018. Topical scope was limited to studies that included both 'sustainability' and 'health care management' in any 'organizational setting' (e.g., hospital, private, corporate, government, community, and education). Papers that focused on macro issues such as the sustainability of health care systems were excluded from the review. 
The review employed the Preferred Reporting Items for Systematic Reviews and Meta-Analyses (PRISMA) to guide the search for documents [38]. A keyword search was conducted in Scopus with the keywords 'sustainability' and 'health care management'. This search yielded 897 documents. The elimination of unwanted types of documents (e.g., surveys, notes, letters) and documents lacking sufficient relevance led to the elimination of 420 documents (Figure 1). The final database consisted of 477 documents. It should be noted that Scopus keyword searches often yield a high percentage of excluded documents for interdisciplinary topics such as sustainable health care management.

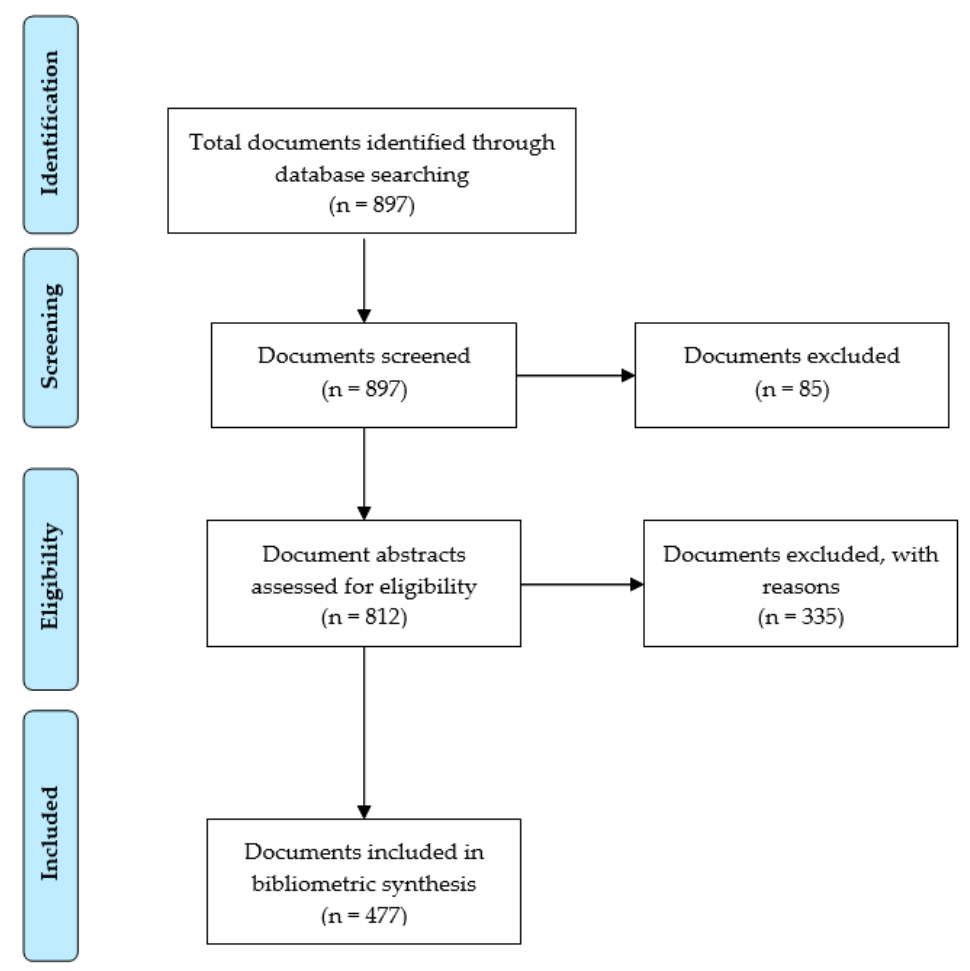

Figure 1. Preferred Reporting Items for Systematic Reviews and Meta-Analyses (PRISMA) flow diagram detailing steps in the identification and screening of sources [38].

\subsection{Data Analysis}

Bibliographic data related to the 477 documents (authors, titles affiliations, citations etc.) were exported and saved for subsequent data analysis. Data analyses included descriptive statistics as well as advanced bibliometric analyses which included citation and co-citation analysis, and 'visualization of similarities' using author co-citation and keyword co-occurrence analysis $[14,16,39,40]$. In addition to Scopus analytical tools and Excel, Tableau, VOSviewer bibliometric software [40] was used to conduct the bibliometric analyses.

\section{Results}

This section reports the results from the bibliometric analysis of the healthcare management for sustainability knowledge base. The four research questions were addressed sequentially below.

\subsection{Descriptive Trends in the SHM Literature}

The first publication sourced for this review was published in 1994. However, scholarly interest in this field did not take off until 2009 when the year-on-year frequency of publications increased by $44 \%$. In subsequent years up until the present, interest in this domain of sustainability research and practice increased significantly with over $90 \%$ of all publications appearing since 2009 and $70 \%$ since 2013 (Figure 2). 


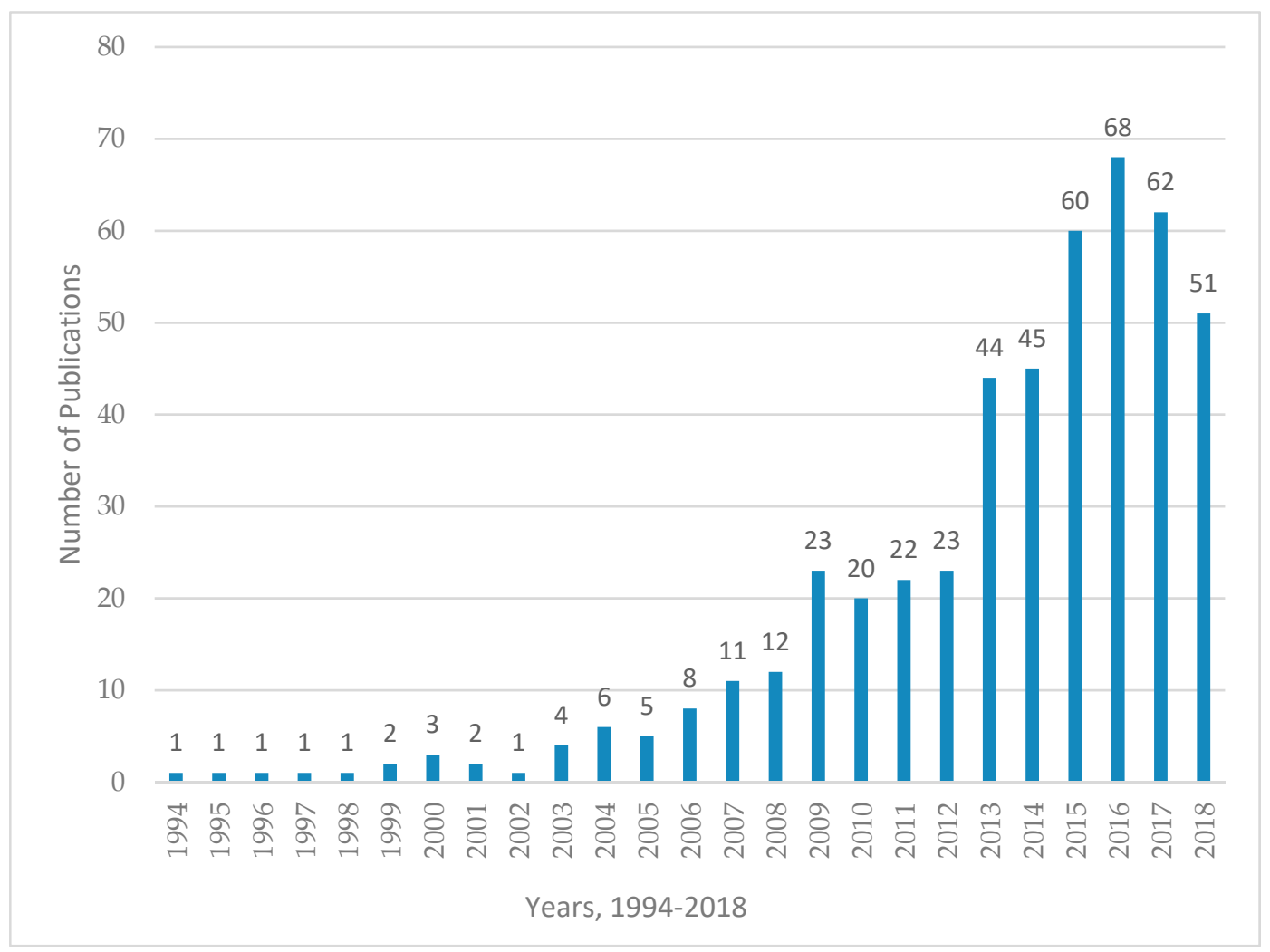

Figure 2. Longitudinal evolution of the sustainable healthcare management (SHM) literature, 1994-2018 $(n=477)$.

Author location was analyzed in order to gain insight into where scholarly interest in SHM research has been located. This body of literature was authored in 75 different countries around the world, thereby affirming worldwide interest in the topic (Figure 3). At the same time, however, we noted that authorship has been focused the United States (USA; 158), United Kingdom (UK; 79), Australia (56) and Canada (52). Scholars affiliated with these four societies generated more than half of the SHM knowledge base collected for this review.

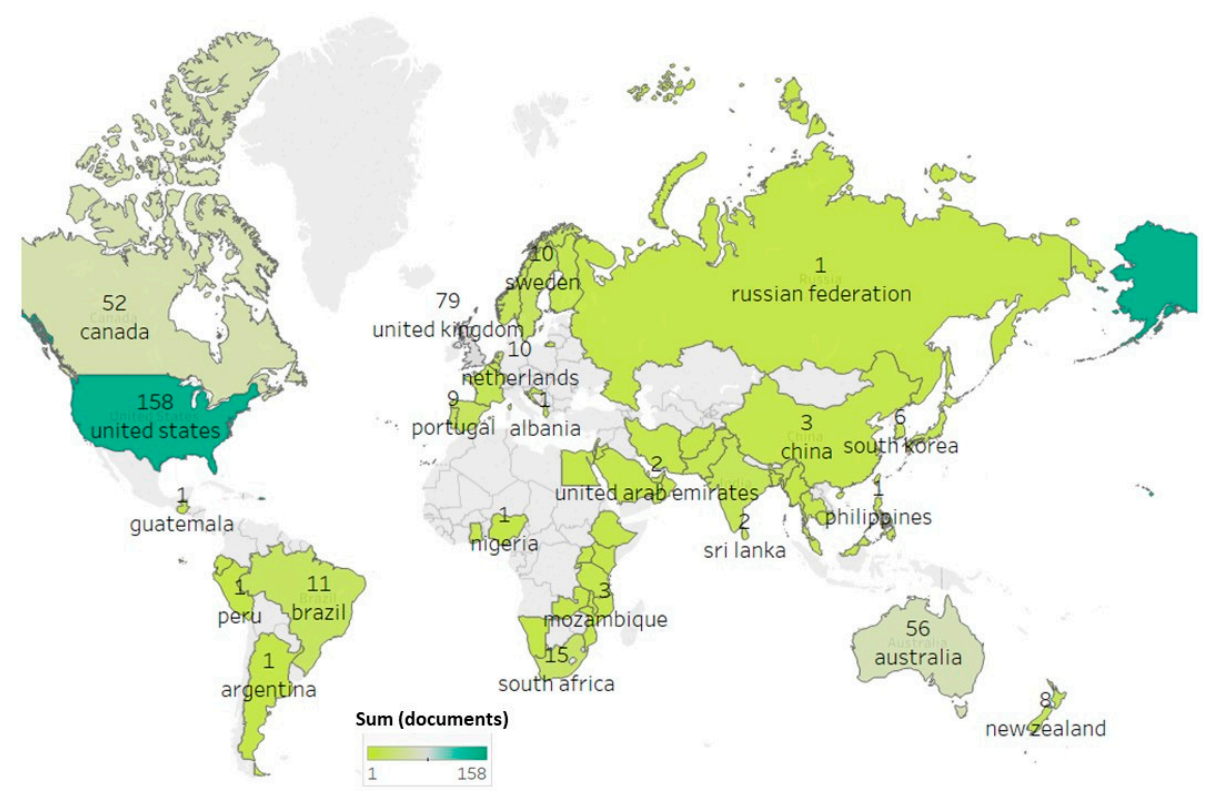

Figure 3. Worldwide distribution of the SHM literature, 1994-2018 $(n=477)$. 


\subsection{Analysis of Influential Authors and Documents}

Scopus citation analysis of authors is shown in Table 1. First, we noted that 1769 authors were listed as authors/co-authors in our review database (not tabled). This implies that this field has attracted interest from a large number of scholars. At the same time, the most frequent contributors to this literature have published only a few papers (Table 1). For example, the most active scholar in this literature, C. Harris from Australia, authored just seven papers. Authors' areas of interest are dispersed across different facets of health care including quality, innovation, management, and policy, as well as environmental science. These results present a picture of an emerging field comprised of authors with hybrid interests and diverse perspectives on sustainable healthcare management.

Table 1. Rank order of the most influential and productive sustainable healthcare management (SHM) authors by Scopus citations and documents published.

\begin{tabular}{|c|c|c|c|c|c|c|}
\hline Author & Nation & Docu-Ments ${ }^{1}$ & $\begin{array}{c}\text { Scopus } \\
\text { Citations }\end{array}$ & $\begin{array}{c}\text { Citations } \\
\text { Per } \\
\text { Document }\end{array}$ & $\begin{array}{l}\text { Scopus } \\
\text { h-Index }\end{array}$ & Focus \\
\hline Braithwaite J. & Australia & 5 & 163 & 32.6 & 41 & Health Care Quality \\
\hline Ritchie J.A. & Canada & 4 & 107 & 26.8 & 24 & Health Care Innovation \\
\hline Harris C. & Australia & 7 & 68 & 9.7 & 8 & Health Care Policy \\
\hline Tudor T.L. & UK & 3 & 65 & 21.7 & $13^{\prime \prime}$ & Environmental Science \\
\hline Denis J.L. & Canada & 3 & 57 & 19.0 & 31 & Health Care Innovation \\
\hline Fleiszer A.R. & Canada & 3 & 57 & 19.0 & 8 & Health Care Innovation \\
\hline Richer M.C. & Canada & 3 & 57 & 19.0 & 13 & Health Care Innovation \\
\hline Semenic S.E. & Canada & 3 & 57 & 19.0 & 13 & Health Care Innovation \\
\hline Allen K. & Australia & 5 & 50 & 10.0 & 11 & Health Care Policy \\
\hline Lettieri E. & Italy & 3 & 44 & 14.7 & 14 & Health Care Management \\
\hline King R. & Australia & 4 & 40 & 10.0 & 6 & Health Care Policy \\
\hline Ramsey W. & Australia & 4 & 40 & 10.0 & 6 & Health Care Policy \\
\hline Mazzocato P. & Sweden & 3 & 39 & 13.0 & 7 & Health Care Management \\
\hline Waller C. & Australia & 4 & 38 & 9.5 & 6 & Health Care Policy \\
\hline Garrubba M. & Australia & 3 & 30 & 10.0 & 5 & Health Care Policy \\
\hline Brooke V. & Australia & 3 & 29 & 9.7 & 3 & Health Care Policy \\
\hline Diallo M.S. & Korea & 3 & 28 & 9.3 & 26 & Environmental Science \\
\hline Fromer N.A. & USA & 3 & 28 & 9.3 & 12 & Environmental Science \\
\hline Jhon M.S. & USA & 3 & 28 & 9.3 & 51 & Environmental Science \\
\hline Roca J. & Spain & 3 & 21 & 7.0 & 70 & Health Care Management \\
\hline
\end{tabular}

The data presented in Table 1 indicate that the most influential scholars in the SHM literature have been Braithwaite (163 Scopus citation), Ritchie (105), Harris (68), Tudor (65), and Denis (57). We note that the citation impact of the authors in Table 1 is relatively low. First, we must clarify that the citations in Table 1 are based solely on citations of each author's documents included in our review database. As suggested by the associated Scopus $h$-index, each author's full corpus of scholarly work goes beyond sustainable healthcare management. In addition, because we used a threshold of 'at least three documents' by an author for this analysis, the table actually omits several other highly-cited authors who authored a single influential document. These authors are, however, highlighted below in Table 1 which presents the most influential documents in this literature.

Table 2 displays the most influential documents in the SHM field, again measured by total Scopus citations. Six documents evidenced more than 100 citations [21,22,41-44]. Taking into account the recency of the SHM literature, these citations are in the moderate range. For readers accustomed to assessing impact by Google Scholar citations, we should clarify that Scopus citations are always significantly lower for the same document or author due to its more selective coverage of literature [37]. Nonetheless, the two metrics tend to correlate very strongly. In addition, the data in Table 2 also highlight the value-added impact that reviews of research have had in advancing this field of inquiry. 
Table 2. Most influential SHM documents by Scopus citations, 1994-2018 ( $n=477)$.

\begin{tabular}{|c|c|c|c|c|c|}
\hline Rank & Author & Document & Focus & $\begin{array}{c}\text { Scopus } \\
\text { Cites }\end{array}$ & $\begin{array}{l}\text { Type of } \\
\text { Paper }\end{array}$ \\
\hline 1 & Franche et al. (2005) & $\begin{array}{l}\text { Workplace-based return-to-work } \\
\text { interventions. [41] }\end{array}$ & Change & 415 & Rev \\
\hline 2 & $\begin{array}{l}\text { Wiltsey Stirman et al. } \\
\text { (2012) }\end{array}$ & $\begin{array}{l}\text { The sustainability of new programs and } \\
\text { innovations. [42] }\end{array}$ & Change & 372 & Rev \\
\hline 3 & Légaré et al. (2010) & $\begin{array}{l}\text { Interventions for improving the } \\
\text { adoption of shared decision making by } \\
\text { health care professionals. [43] }\end{array}$ & Social & 277 & Rev \\
\hline 4 & Vest \& Gamm (2009) & $\begin{array}{l}\text { A critical review of the research } \\
\text { literature on Six Sigma, Lean and } \\
\text { Studer Group's Hardwiring Excellence } \\
\text { in the U.S. [21] }\end{array}$ & Economic & 129 & Rev \\
\hline 5 & $\begin{array}{l}\text { D'Andreamatteo et al. } \\
\text { (2015) }\end{array}$ & $\begin{array}{l}\text { Lean in health care: A comprehensive } \\
\text { review. [22] }\end{array}$ & Economic & 114 & $\operatorname{Rev}$ \\
\hline 6 & $\begin{array}{l}\text { Cunningham et al. } \\
\text { (2012) }\end{array}$ & $\begin{array}{l}\text { Health professional networks as a } \\
\text { vector for improving health care quality } \\
\text { and safety: A systematic review. [44] }\end{array}$ & Social & 107 & Rev \\
\hline 7 & Jordan et al. (2008) & $\begin{array}{l}\text { Enhancing patient engagement in } \\
\text { chronic disease self-management } \\
\text { support initiatives in Australia. [45] }\end{array}$ & Social & 94 & Con \\
\hline 8 & Huryk (2010) & $\begin{array}{l}\text { Factors influencing nurses' attitudes } \\
\text { towards health care information } \\
\text { technology. [46] }\end{array}$ & Change & 90 & Rev \\
\hline 9 & $\begin{array}{l}\text { Lee \& Cummings } \\
\text { (2008) }\end{array}$ & $\begin{array}{l}\text { Factors influencing job satisfaction of } \\
\text { front line nurse managers [47] }\end{array}$ & Change & 88 & $\operatorname{Rev}$ \\
\hline 10 & Ulrich et al. (2011) & $\begin{array}{l}\text { A conceptual framework for the } \\
\text { domain of evidence-based design. [48] }\end{array}$ & Economic & 88 & Con \\
\hline
\end{tabular}

In terms of sustainability foci, the highly-cited documents were equally distributed among change, social/health, and economics. The most highly-cited document, Franche et al. [41], was a systematic review of strategies used by health care organizations that enable patients to return to work successfully. They found that human resource management strategies which incorporate, "work accommodation offers and contact between healthcare provider and workplace" can reduce both cost and disability duration (p. 607). However, the sustainability of results and impact on quality of life outcomes from the management intervention were limited.

Wiltsey Stirman et al. [42] reviewed research on the sustainability of health programs and innovations beyond initial adoption and implementation phases. This review reoriented discourse in the field of health care management by drawing attention to the 'sustainability' of interventions using evidence-based implementation techniques. The authors concluded that prior research, even evidence-based studies, tended to rely on short-term measures of outcomes. They offered recommendations both with respect to research methods and the range of sustainability outcomes that should be incorporated into future studies 2 .

The research review of Légaré et al. [43] on 'shared decision-making' in health care management complemented a focus on the sustainability of health care outcomes with consideration of the 'social dimension' of sustainability. They examined how the adoption of a common management strategy, shared decision making, can improve the sustainability of health care outcomes. They conclude that given the potential of this 'management intervention' for improving the sustainability of health care outcomes, it warrants greater attention from health care professionals.

The next two highly-cited documents [21,22] both reviewed research on the adoption of 'lean health care' approaches. These included widely adopted quality management systems such as Lean Production, Six Sigma, and Studer's Hardwiring Excellence for health care organization. Vest and Gamm concluded that "the implementations of these transformation strategies were successful in improving a variety of healthcare related processes and outcomes" (p. 35). At the same time however, the authors noted a number of methodological limitations that limit this conclusion, such as failure 
to take into account the existing organizational culture. We would add that both of these reviews of 'lean health care management' relied either solely [21] or heavily [22] on documents sourced from Western countries.

\subsection{Intellectual Structure of the Healthcare Management Knowledge Base}

Scholars employing science mapping methods of review have also inquired into the intellectual structure' of different fields of study [15]. Intellectual structure refers to the key theoretical and empirical lines of inquiry, or 'schools of thought' that define a field of study. We employed author co-citation analysis in VOSviewer to create a network map that offers insight into the intellectual structure of the SHM knowledge base.

Co-citation analysis examined the frequency with which pairs of authors were cited together in the reference lists of the 477 documents in the review database. Thus co-citation analysis scans a much larger body of literature (i.e., the references cited by authors of the review documents) than the Scopus citation analysis. Scholars employing co-citation analysis propose that authors who are frequently co-cited by other scholars share a similarity in research perspective. Moreover, by examining the frequency of 'author co-citations', VOSviewer software is able to produce a network map that 'visualizes similarities' among the authors cited in our SHM database [40].

VOSviewer was set to a threshold of at least 15 author co-citations, which yielded a display of 131 scholars on the co-citation map (Figure 4). In Figure 4, the larger bubbles indicate influential scholars based on higher co-citation frequency. The colored clusters group scholars into schools of thought based on co-citation relationships. The author co-citation map in Figure 4 shows that the intellectual structure of the SHM literature is comprised of three schools of thought: 'innovations in managing health care operations' (green cluster), 'sustainable change in health care services' (red cluster), and 'prioritizing and allocating health care resources' (blue cluster).

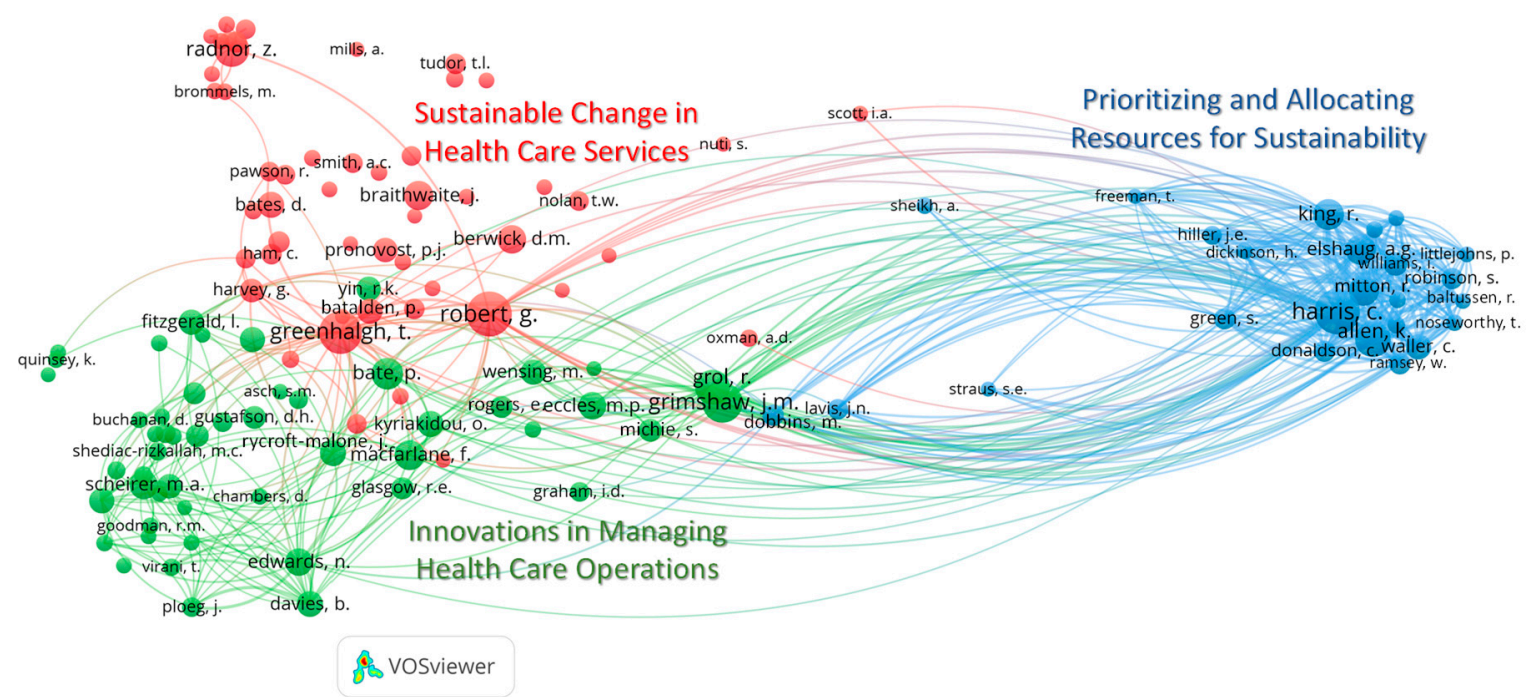

Figure 4. Author co-citation analysis map of the healthcare management for sustainability literature (threshold 15, display 131 authors, cluster resolution 90\%, 3 clusters).

The 'sustainable change in health care services' (red cluster) is the largest school of thought consisting of 53 scholars [49-60]. Key scholars associated with this school include Robert with 77 co-citations [11,51,52], Greenhalgh with 72 co-citations [12,49,50], and Radnor with 53 co-citations. Greenhalgh and Robert authored two highly co-cited papers (not tabled): 'Diffusion of innovations in service organizations: Systematic review and recommendations' [11] and 'Diffusion of innovations in health service organizations: A systematic literature review' [53]. These papers examined how the sustainability of innovations in health care organization and health service delivery were defined and could be measured. 
Recent literature in this school of thought has broadened the scope of change implementation by focusing on business transformation strategies designed to improve operational processes and outcomes for health care organizations. For example, authors such as Radnor, Baithwaite, Smith and Berwick have explored the potential and effects of implementing business processes designed to reduce waste and improve the quality of care [57-62]. Evidence-based practices and implementation have been studied within the scholarly literature in this discipline [11,20]. These not only improve care for patient safety, but also operational effectiveness, efficiency, quality, and cost reduction [21,22,57]. Other recent trends in this literature include the implementation of technological innovations such as telemedicine, health care technology, and health information technology for operational improvement and cost reduction [61,62]. Nonetheless, evidence of sustainable results from efforts to implement these innovations is largely lacking [52]. Moreover, the literature in this school of thought shows only occasional concern with environmental sustainability (e.g., waste management) and none for social sustainability.

The 'innovations in managing health care operations' (green cluster) school is the next largest cluster, comprised of 51 scholars. Key scholars working in this schools include Grimshaw with 66 co-citations [63-66], Grol with 52 co-citations [64,65], Bate with 46 co-citations [11,49,67], McFarlen with 42 co-citations, and Scheirer with 39 co-citations $[13,68,69]$. Scholars located in this school of thought evidence a dual focus on the use of evidence-based innovations for managing healthcare operations and services. Research conducted by Grimshaw and Grol has sought to translate evidence-based research into procedures for clinical practice aimed at improving the quality of patient care $[64,65]$. Notably, this this research has paid particular attention to change management in the implementation process $[63,64]$. Scheirer's research has explored factors that impact the sustainability of health care programs and innovations. This research has identified five key sustainability factors: adaptability, project champion, alignment with organization's mission and procedures, and benefits to stakeholder support [13].

The 'prioritizing and allocating resources for sustainability' school (blue cluster) is the smallest cluster comprised of 25 influential authors. This school is concerned with health care decision-making, policy and planning. Key authors include five Australian scholars: Harris with 77 co-citations [70-77], Allen with 53 co-citations [70-72,75-77], King with 44 co-citations [70-72,75-77], Elshaung with 42 co-citations [74,78-80], and Mitton with 42 co-citations [78,81]. Key literature within this School centers on a series of 11 research papers published under the acronym, 'SHARE' or 'Sustainability in health care by allocating resources effectively' [70,72-77,82-84]. These papers investigated the process of disinvestment in the Australian health services network using an evidence-based approach. This involved studying the decision making process of allocating resources within a system-level infrastructure as opposed to individual projects. The project sought to take into consideration financial (e.g., clinical purchasing, capital procurement) and non-financial resources (e.g., use of drug equivalent protocol development) to optimize health care outcomes.

\subsection{Topical Foci of the Healthcare Management for Sustainability Knowledge Base}

Co-word analysis was used to analyze the topics studied in the SHM literature. The first used VOSviewer to identify the most frequent keywords. As indicated in the density map (Figure 5), the most frequently occurring keywords were organization and management (261), health care delivery (119), healthcare (92), sustainability (86), health care quality (85), organization (81), standard (78), and total quality management (74). This pattern of results reinforces that findings from author co-citation analysis which highlighted the dominance of sustainability s viewed from an economic perspective. 


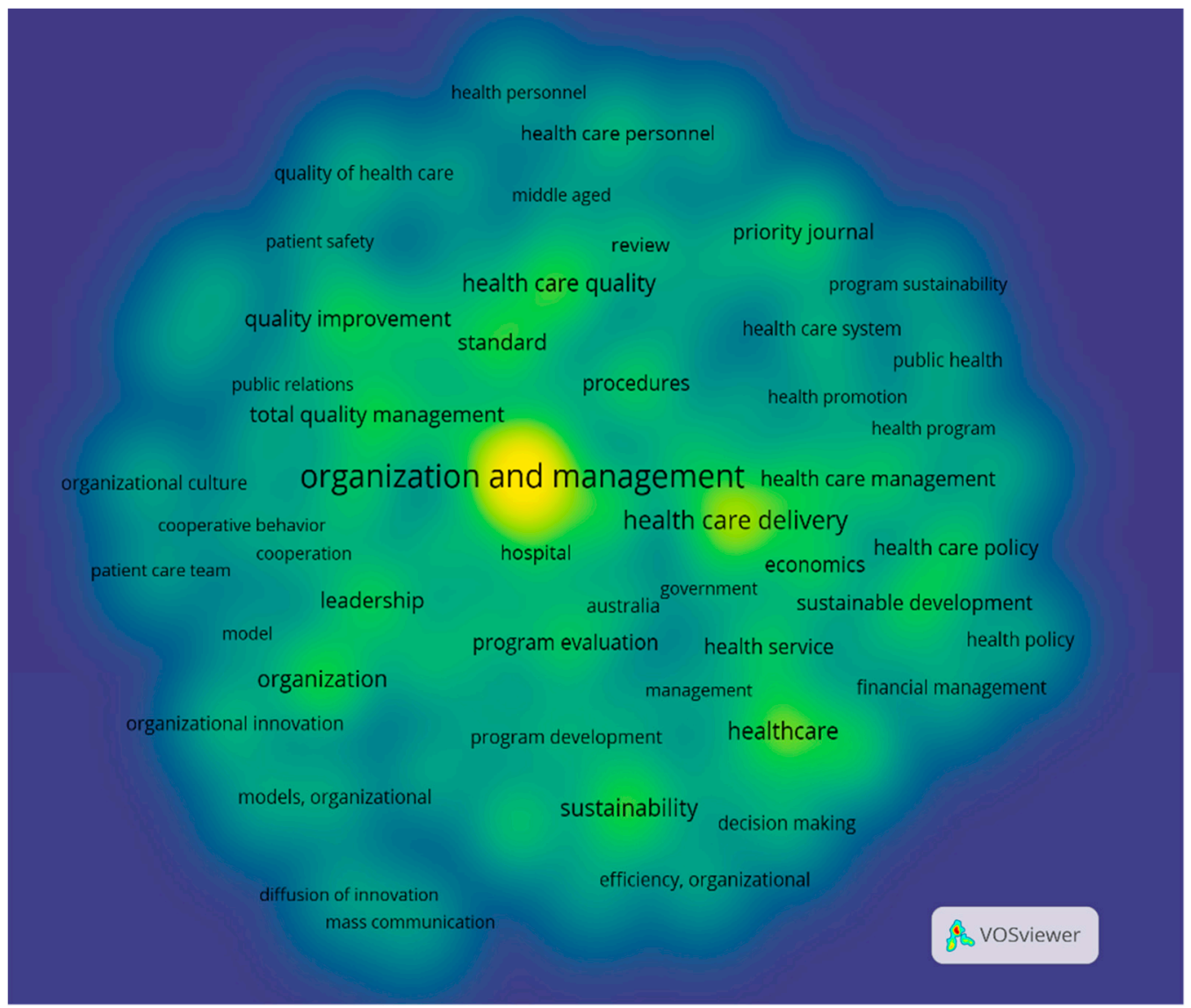

Figure 5. Keyword density heat map for the SHM literature, 1994-2018 (threshold 20 occurrences, display 78 keywords).

Next a 'temporal co-word map' (Figure 6) was generated in VOSviewer using a threshold of at least 20 co-occurrences [40]. The temporal co-word analysis examines the time distribution of keywords based on the date of document publication. Yellow/lighter shaded bubbles are associated with the most recent topics of interest to scholars in this field, while the darker bubbles signify topics that were popular in the earlier periods. Interpretation of this map centers on the size of the bubble (frequency), color (recency), and location (relationship to other topics).

'Organization and management' holds the center position on the map, has the most links to other topics, and is of current interest. This finding reprises the discussion of the intellectual structure of the knowledge base in which all three schools of thought had a strong focus on organization and management of healthcare services.

We also noted a cluster of recent topics focused on "leadership and change" (green cluster) linked to 'organization and management'. This theme consisted of the keywords 'leadership', 'organization', 'sustainability', 'patient care', and 'program evaluation'. This reflects interest in leading changes for sustainability in organizations.

A second cluster of recent keywords, also linked to 'organization and management', focused on different aspects of "quality of patient care" (blue cluster). These include 'standards', 'quality improvement', 'total quality management', 'quality of health care', 'patient safety', and 'systematic review'. This theme mirrors topics studied within the first and second schools of thought and reaffirms their currency.

Finally, a third theme comprised of current topics centered on the theme of "sustainability of health care delivery" (red cluster) consists of 'healthcare delivery', 'sustainability', 'economic', 'procedure', 'program sustainability', and 'sustainable development'. Again, this reprises the earlier discussion of the third school of thought, prioritizing and allocating resources for sustainability. 
Overall, the temporal co-word analysis extends the earlier finding by affirming that current interest in the SHM field is primarily concerned with the sustainability of programs, innovations and change (see 'sustainability' and program sustainability'. There is no evidence offered by either form of co-word analysis that social or environmental sustainability has gained traction in this literature.

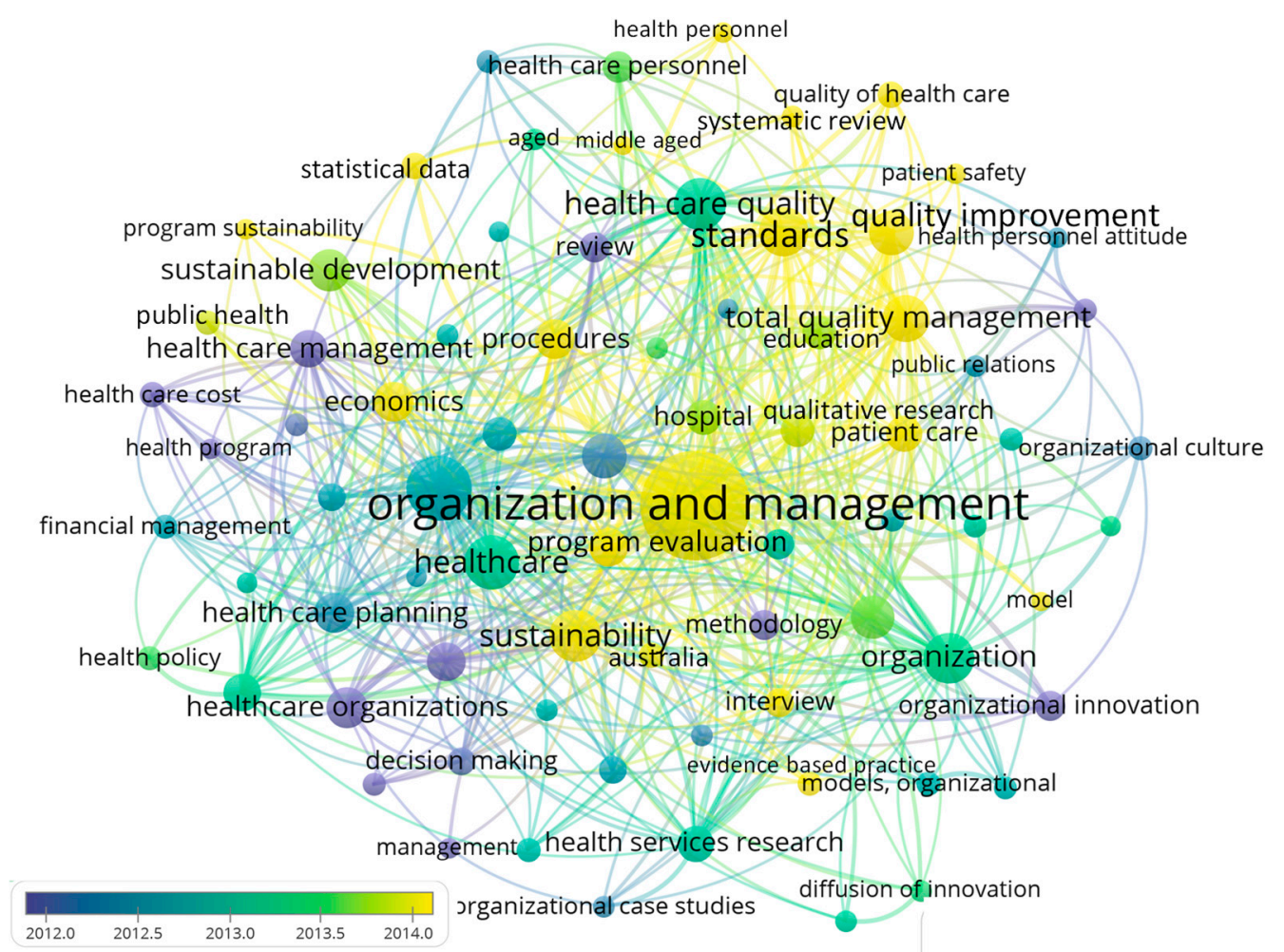

Figure 6. Temporal co-word map of the SHM literature, 1994-2018 (threshold 20 occurrences, display 78 keywords).

\section{Discussion}

This section presents limitations of the review and discusses the authors' interpretation of the findings.

\subsection{Limitations}

The first limitation of the study arises from the use of a quantitative method to review documents in the SHM field. The review relied on the analysis of bibliographic data associated with the documents rather than examination of research findings. Thus, the review's implications are limited to broad directions on the development of the field rather than synthesis of results of studies.

A second limitation follows from the definition of the field of healthcare management. SHM is an emerging field whose conceptual boundaries have yet to become well established. Therefore, our use of the search term 'sustainability' tended to yield documents associated with program and innovation sustainability as opposed to environmental and social sustainability. However, while this represents a kind of limitation, our bibliometric review has established the current 'state-of-the-field' with respect to 'sustainability' in healthcare management. Thus, our findings can be used as a benchmark for future reviews that track the development of this field.

\subsection{Conclusion and Discussion}

This review of research revealed the limited size of the literature on healthcare management for sustainability. Although the first relevant scholarly work was published in 1994, most of this 
literature has accumulated in the past 10 years. This is due to increasing recognition of the importance of sustainability across different professional fields and the promotion of the SDGs by the UN.

Our analysis of the global geographic distribution of SHM literature confirmed that interest in this domain is global in scope. At the same time, however, we noted that knowledge on sustainable healthcare management has been predominantly generated by scholars in the USA, UK, Australia, and Canada with a paucity of contributions from developing societies. This unbalanced distribution of research suggests a gap in this literature given the importance of health care sustainability in the social and economic progress of developing societies. We therefore urge scholars to prioritize research on sustainability in healthcare management in developing countries. Relevant concepts that can be applied in this research includes stakeholder theory [85,86], corporate social responsibility (CSR) [87], corporate shared value [88], green supply chain management [89,90], a sustainable development philosophy initiated by the King Rama IX of Thailand, called, Sufficiency Economy Philosophy (SEP) [91] and learning theory [92].

Citation analysis identified influential authors writing on this issue. These were affiliated with four developed countries including the United States (Fromer, Jhon), United Kingdom (Tudor), Australia (Braithwaite, Harris, Allen, King, Ramsey, Waller, Brooke, Garrubba), and Canada (Ritchie, Danis, Fleiszer, Richer, Semenic). These highly-cited scholars have tended to focus on healthcare policy, healthcare innovation, healthcare management, and the environmental sciences to healthcare delivery.

A central contribution of this review lies in the empirical analysis of the intellectual structure of this emerging literature. Identification of the schools of thought that comprise this inter-disciplinary literature extends findings reported in prior reviews of research. More specifically, author co-citation analysis revealed three schools of thought in the SHM literature: (1) sustainable change in health care services, (2) innovations in managing health care operations, and (3) prioritizing and allocating resources for sustainability. The science map of the SHM literature highlighted both the micro-level focus on healthcare management in organizations $[11,13,49,63,66]$, as well as macro-level issues in healthcare systems [70-77].

The first school of thought, sustainable change in health care services, surfaced factors such as clear vision, program leadership, corporate culture, and ongoing capacity development that enable staff to adapt to changing requirements and conditions $[3,72,85,86]$. The second school of thought, innovations in managing health care operations, highlighted the role that innovation and technology have come to play in increasing access to quality care, and improving operational quality in healthcare organizations [49]. Our study supported the future research direction of Chauhan and Singh [18] on the advancement of operations management techniques to support the sustainability field.The last school of thought, prioritizing and allocating resources for sustainability, highlighted the importance of health policy $[28,78,93]$. Limited health care resources, especially financial resources, should be allocated to create the maximum impact for accessibility and quality.

The recent themes of the SHM field shown in the density map reflect recent priorities of research on healthcare management: (1) health policy for sustainable development with the economic outcome and (2) management with quality improvement and leadership for organizations. The findings confirmed the importance and emergent needs of soft skills (leadership and changes) and hard skills (quality improvement systems) in managing for sustainability. However, we noted that these trends emphasize the economic (e.g., quality, efficiency) side of sustainability. Based on the documents reviewed in this paper, the social and environmental aspects have yet to achieve equal attention.

Thus, the key finding from this review lies in the need for scholars to incorporate social and environmental outcomes in future studies. With regard to social outcomes, we did find some studies focusing on the provision of healthcare services to aging societies, an important social issue. However, this only begins to touch on the many social outcomes of healthcare that bear on sustainability. With respect to environmental concerns, we ask how are healthcare organizations taking advantage of sustainable supply chain management, recycling, and waste management? How are concepts such as life cycle assessment and the circular economy changing traditional approaches to managing healthcare 
organizations? These deficits in the SHM literature again highlight the recent emergence of this literature and an as yet incomplete embrace of fundamental sustainability issues.

Author Contributions: Conceptualization, P.P. and P.H.; methodology, P.P. and P.H.; data analysis, P.P. and P.H.; writing —original draft preparation, P.P.; writing—review and editing, P.H. All authors have read and agreed to the published version of the manuscript.

Funding: This research was funded by Thailand Sustainable Development Foundation, Bangkok, Thailand grant number (008/2561).

Acknowledgments: This research was supported by research grant from the Thailand Sustainable Development Foundation. The authors would like to thank Borwornsom Leelapan for valuable feedback for improving the quality of this paper.

Conflicts of Interest: The authors declare no conflict of interest.

\section{References}

1. Khandakar, S.; Saad Andaleeb, S.; Siddiqui, N. Doctors' service orientation in public, private, and foreign hospitals. Int. J. Health Care Qual. Assur. 2007, 20, 253-263.

2. Greenhalgh, T.; Macfarlane, F.; Barton-Sweeney, C.; Woodard, F. “If We Build It, Will It Stay?” A Case Study of the Sustainability of Whole-System Change in London. Milbank Q. 2012, 90, 516-547. [CrossRef] [PubMed]

3. Ament, S.M.C.; Gillissen, F.; Maessen, J.M.C.; Dirksen, C.D.; van der Weijden, T.; von Meyenfeldt, M.F. Sustainability of healthcare innovations (SUSHI): Long term effects of two implemented surgical care programmes (protocol). BMC Health Serv. Res. 2012, 12, 423. [CrossRef] [PubMed]

4. Goh, C.Y.; Marimuthu, M. The Path towards Healthcare Sustainability: The Role of Organisational Commitment. Procedia Soc. Behav. Sci. 2016, 224, 587-592. [CrossRef]

5. Ramirez, B.; West, D.J.; Costell, M.M. Development of a culture of sustainability in health care organizations. J. Health Organ. Manag. 2013, 27, 665-672. [CrossRef] [PubMed]

6. GGHC-Tools: Green Guide for Health Care Version 2.2: Overview. Available online: https://www.gghc.org/ tools.2.2overview.php (accessed on 9 June 2019).

7. Dpicampaigns. About the Sustainable Development Goals. Available online: https://www.un.org/ sustainabledevelopment/sustainable-development-goals/ (accessed on 9 June 2019).

8. SDGs: Sustainable Development Knowledge Platform. Available online: https://sustainabledevelopment.un. org/sdgs (accessed on 9 June 2019).

9. Ramirez, B.; Oetjen, R.M.; Malvey, D. Sustainability and the health care manager: Part I. Health Care Manag. 2011, 30, 133-138. [CrossRef] [PubMed]

10. Ramirez, B.; Oetjen, R.M.; Malvey, D. Sustainability and the health care manager: Part II. Health Care Manag. 2011, 30, 261-265. [CrossRef]

11. Greenhalgh, T.; Robert, G.; Macfarlane, F.; Bate, P.; Kyriakidou, O. Diffusion of innovations in service organizations: Systematic review and recommendations. Milbank Q. 2004, 82, 581-629. [CrossRef] [PubMed]

12. Gruen, R.L.; Elliott, J.H.; Nolan, M.L.; Lawton, P.D.; Parkhill, A.; McLaren, C.J.; Lavis, J.N. Sustainability science: An integrated approach for health-programme planning. Lancet Lond. Engl. 2008, 372, 1579-1589. [CrossRef]

13. Scheirer, M.A. Is Sustainability Possible? A Review and Commentary on Empirical Studies of Program Sustainability. Am. J. Eval. 2005, 26, 320-347. [CrossRef]

14. Zupic, I.; Čater, T. Bibliometric Methods in Management and Organization. Organ. Res. Methods 2015, 18, 429-472. [CrossRef]

15. Nerur, S.P.; Rasheed, A.A.; Natarajan, V. The intellectual structure of the strategic management field: An author co-citation analysis. Strateg. Manag. J. 2008, 29, 319-336. [CrossRef]

16. White, H.D.; McCain, K.W. Visualizing a discipline: An author co-citation analysis of information science, 1972-1995. J. Am. Soc. Inf. Sci. 1998, 49, 327-355.

17. Sheth, A.; Price, A.D.F.; Glass, J.; Achour, N. Reviewing the sustainability of existing healthcare facilities. In Proceedings of the 23rd Annual Conference of Association of Researchers in Construction Management (ARCOM), Cardiff, UK, 3-5 September 2008; pp. 1193-1202.

18. Chauhan, A.; Singh, A. Healthcare waste management: A state-of-the-art literature review. Int. J. Environ. Waste Manag. 2016, 18, 120-144. [CrossRef] 
19. Nichols, A. Sustainable Practice and Behaviour change in Healthcare Waste Management: A Review of the Literature. In Proceedings of the 1st World Sustainability Forum, Basel, Switzerland, 1-30 November 2011; p. 551.

20. Proctor, E.; Luke, D.; Calhoun, A.; McMillen, C.; Brownson, R.; McCrary, S.; Padek, M. Sustainability of evidence-based healthcare: Research agenda, methodological advances, and infrastructure support. Implement. Sci. 2015, 10, 88. [CrossRef] [PubMed]

21. Vest, J.R.; Gamm, L.D. A critical review of the research literature on Six Sigma, Lean and StuderGroup's Hardwiring Excellence in the United States: The need to demonstrate and communicate the effectiveness of transformation strategies in healthcare. Implement. Sci. 2009, 4, 35. [CrossRef] [PubMed]

22. D'Andreamatteo, A.; Ianni, L.; Lega, F.; Sargiacomo, M. Lean in healthcare: A comprehensive review. Health Policy 2015, 119, 1197-1209. [CrossRef]

23. Anuar, A.; Saad, R.; Yusoff, R.Z. Sustainability through lean healthcare and operational performance in the private hospitals: A proposed framework. Int. J. Supply Chain Manag. 2018, 7, 221-227.

24. Leape, L.L.; Berwick, D.; Clancy, C.; Conway, J.; Gluck, P.; Guest, J.; Lawrence, D.; Morath, J.; O’Leary, D.; O'Neill, P.; et al. Transforming healthcare: A safety imperative. BMJ Qual. Saf. 2009, 18, 424-428. [CrossRef]

25. Shediac-Rizkallah, M.C.; Bone, L.R. Planning for the sustainability of community-based health programs: Conceptual frameworks and future directions for research, practice and policy. Health Educ. Res. 1998, 13, 87-108. [CrossRef]

26. Pinzone, M.; Lettieri, E.; Masella, C. Sustainability in healthcare: Combining organizational and architectural levers. Int. J. Eng. Bus. Manag. 2012, 4, 38. [CrossRef]

27. Rich, C.R.; Singleton, J.K.; Wadhwa, S.S. Sustainability for Healthcare Management: A Leadership Imperative; Routledge: London, UK, 2018.

28. Robinson, S.; Williams, I.; Dickinson, H.; Freeman, T.; Rumbold, B. Priority-setting and rationing in healthcare: Evidence from the English experience. Soc. Sci. Med. 2012, 75, 2386-2393. [CrossRef] [PubMed]

29. Robinson, S.; Williams, I.; Spence, K.; Daniels, T. Tackling disinvestment in health care services: The views of resource allocators in the English NHS. J. Health Organ. Manag. 2013, 27, 762-780.

30. Pasqualine, A.; Plytiuk, C.F.; da Costa, S.E.G.; de Lima, E.P. Performance Management in Healthcare: A bibliometric review. In Proceedings of the Institute of Industrial and Systems Engineers (IISE), Orlanda, FL, USA, 19-23 May 2012; p. 1.

31. Bradea, I.; Delcea, C.; Paun, R. Healthcare Risk Management Analysis-A Bibliometric Approach. J. East. Eur. Res. Bus. Econ. 2015, 2015, 1-11. [CrossRef]

32. Koseoglu, M.A.; Akdeve, E.; Gedik, İ; Bertsch, A. A bibliometric analysis of strategic management articles in healthcare management literature: Past, present, and future. Int. J. Healthc. Manag. 2015, 8, 27-33. [CrossRef]

33. Adunlin, G.; Diaby, V.; Xiao, H. Application of multicriteria decision analysis in health care: A systematic review and bibliometric analysis. Health Expect. 2015, 18, 1894-1905. [CrossRef]

34. Mongeon, P.; Paul-Hus, A. The journal coverage of Web of Science and Scopus: A comparative analysis. Scientometrics 2016, 106, 213-228. [CrossRef]

35. Hallinger, P.; Kovačević, J. A Bibliometric Review of Research on Educational Administration: Science Mapping the Literature, 1960 to 2018. Rev. Educ. Res. 2019, 89, 335-369. [CrossRef]

36. Archambault, É.; Campbell, D.; Gingras, Y.; Larivière, V. Comparing bibliometric statistics obtained from the Web of Science and Scopus. J. Am. Soc. Inf. Sci. Technol. 2009, 60, 1320-1326. [CrossRef]

37. Falagas, M.E.; Pitsouni, E.I.; Malietzis, G.A.; Pappas, G. Comparison of PubMed, Scopus, Web of Science, and Google Scholar: Strengths and weaknesses. FASEB J. 2008, 22, 338-342. [CrossRef]

38. Moher, D. Preferred Reporting Items for Systematic Reviews and Meta-Analyses: The PRISMA Statement. Ann. Intern. Med. 2009, 151, 264. [CrossRef] [PubMed]

39. Small, H. Visualizing science by citation mapping. J. Am. Soc. Inf. Sci. 1999, 50, 799-813. [CrossRef]

40. van Eck, N.J.; Waltman, L. Citation-based clustering of publications using CitNetExplorer and VOSviewer. Scientometrics 2017, 111, 1053-1070. [CrossRef] [PubMed]

41. Franche, R.-L.; Cullen, K.; Clarke, J.; Irvin, E.; Sinclair, S.; Frank, J.; Cole, D.; Dacombe, J.; Guzman, J.; Hogg-Johnson, S.; et al. Workplace-based return-to-work interventions: A systematic review of the quantitative literature. J. Occup. Rehabil. 2005, 15, 607-631. [CrossRef] [PubMed] 
42. Wiltsey Stirman, S.; Kimberly, J.; Cook, N.; Calloway, A.; Castro, F.; Charns, M. The sustainability of new programs and innovations: A review of the empirical literature and recommendations for future research. Implement. Sci. 2012, 7, 17. [CrossRef]

43. Légaré, F.; Ratté, S.; Stacey, D.; Kryworuchko, J.; Gravel, K.; Graham, I.D.; Turcotte, S. Interventions for improving the adoption of shared decision making by healthcare professionals. Cochrane Database Syst. Rev. Online 2010, 5, CD006732.

44. Cunningham, F.C.; Ranmuthugala, G.; Plumb, J.; Georgiou, A.; Westbrook, J.I.; Braithwaite, J. Health professional networks as a vector for improving healthcare quality and safety: A systematic review. BMJ Qual. Saf. 2012, 21, 239-249. [CrossRef]

45. Jordan, J.E.; Briggs, A.M.; Brand, C.A.; Osborne, R.H. Enhancing patient engagement in chronic disease self-management support initiatives in Australia: The need for an integrated approach. Med. J. Aust. 2008, 189, S9-S13. [CrossRef]

46. Huryk, L.A. Factors influencing nurses' attitudes towards healthcare information technology. J. Nurs. Manag. 2010, 18, 606-612. [CrossRef]

47. Lee, H.; Cummings, G.G. Factors influencing job satisfaction of front line nurse managers: A systematic review. J. Nurs. Manag. 2008, 16, 768-783. [CrossRef]

48. Ulrich, R.S.; Berry, L.L.; Quan, X.; Parish, J.T. A conceptual framework for the domain of evidence-based design. Health Environ. Res. Des. J. 2011, 4, 95-114. [CrossRef] [PubMed]

49. Greenhalgh, T.; Robert, G.; Bate, P.; Macfarlane, F.; Kyriakidou, O. Diffusion of Innovations in Health Service Organisations: A Systematic Literature Review; John Wiley \& Sons: New York, NY, USA, 2008.

50. Greenhalgh, T.; Robert, G.; MacFarlane, F.; Bate, P.; Kyriakidou, O.; Peacock, R. Storylines of research in diffusion of innovation: A meta-narrative approach to systematic review. Soc. Sci. Med. 2005, 61, 417-430. [CrossRef] [PubMed]

51. Robert, G.; Morrow, E.; Maben, J.; Griffiths, P.; Callard, L. The adoption, local implementation and assimilation into routine nursing practice of a national quality improvement programme: The Productive Ward in England. J. Clin. Nurs. 2011, 20, 1196-1207. [CrossRef] [PubMed]

52. Staines, A.; Thor, J.; Robert, G. Sustaining improvement? The 20-year jönköping quality improvement program revisited. Qual. Manag. Health Care 2015, 24, 21-37. [CrossRef]

53. Greenhalgh, T.; Robert, G.; Bate, P.; Macfarlane, F.; Kyriakidou, O. Diffusion of Innovations in Health Service Organisations: A Systematic Literature Review; John Wiley \& Sons: New York, NY, USA, 2008.

54. Wong, G.; Greenhalgh, T.; Westhorp, G.; Pawson, R. Realist methods in medical education research: What are they and what can they contribute? Med. Educ. 2012, 46, 89-96. [CrossRef] [PubMed]

55. Best, A.; Greenhalgh, T.; Lewis, S.; Saul, J.E.; Carroll, S.; Bitz, J. Large-system transformation in health care: A realist review. Milbank Q. 2012, 90, 421-456. [CrossRef]

56. Fraser, S.W.; Greenhalgh, T. Complexity science: Coping with complexity: Educating for capability. Br. Med. J. 2001, 323, 799-803. [CrossRef]

57. Radnor, Z.J.; Holweg, M.; Waring, J. Lean in healthcare: The unfilled promise? Soc. Sci. Med. 2012, 74, 364-371. [CrossRef]

58. Braithwaite, J.; Marks, D.; Taylor, N. Harnessing implementation science to improve care quality and patient safety: A systematic review of targeted literature. Int. J. Qual. Health Care 2014, 26, 321-329. [CrossRef]

59. Braithwaite, J.; Testa, L.; Lamprell, G.; Herkes, J.; Ludlow, K.; McPherson, E.; Campbell, M.; Holt, J. Built to last? The sustainability of health system improvements, interventions and change strategies: A study protocol for a systematic review. BMJ Open 2017, 7, e018568. [CrossRef]

60. Braithwaite, J.; Mannion, R.; Matsuyama, Y.; Shekelle, P.G.; Whittaker, S.; Al-Adawi, S.; Ludlow, K.; James, W.; Ting, H.P.; Herkes, J.; et al. The future of health systems to 2030: A roadmap for global progress and sustainability. Int. J. Qual. Health Care 2018, 30, 823-831. [CrossRef] [PubMed]

61. Smith, A.C.; Gray, L.C. Telemedicine across the ages. Med. J. Aust. 2009, 190, 15-19. [CrossRef] [PubMed]

62. Smith, A.C.; Scuffham, P.; Wootton, R. The costs and potential savings of a novel telepaediatric service in Queensland. BMC Health Serv. Res. 2007, 7, 35. [CrossRef] [PubMed]

63. Grimshaw, J.M.; Eccles, M.P. Is evidence-based implementation of evidence-based care possible? Med. J. Aust. 2004, 180, S50-S51. [CrossRef] [PubMed]

64. Grol, R.; Grimshaw, J. From best evidence to best practice: Effective implementation of change in patients' care. Lancet 2003, 362, 1225-1230. [CrossRef] 
65. Grol, R.; Grimshaw, J. Evidence-based implementation of evidence-based medicine. Jt. Comm. J. Qual. Improv. 1999, 25, 503-513. [CrossRef]

66. Grimshaw, J.M.; Thomas, R.E.; MacLennan, G.; Fraser, C.; Ramsay, C.R.; Vale, L.; Whitty, P.; Eccles, M.P.; Matowe, L.; Shirran, L.; et al. Effectiveness and efficiency of guideline dissemination and implementation strategies. Int. J. Technol. Assess. Health Care 2005, 21, 149. [CrossRef]

67. Bate, P.; Robert, G.; Bevan, H. The next phase of healthcare improvement: What can we learn from social movements? BMJ Qual. Saf. 2004, 13, 62-66. [CrossRef]

68. Scheirer, M.A. Linking sustainability research to intervention types. Am. J. Public Health 2013, 103, e73-e80. [CrossRef]

69. Scheirer, M.A.; Dearing, J.W. An agenda for research on the sustainability of Public Health Programs. Am. J. Public Health 2011, 101, 2059-2067. [CrossRef]

70. Harris, C.; Green, S.; Ramsey, W.; Allen, K.; King, R. Sustainability in Health care by allocating resources effectively (SHARE) 1: Introducing a series of papers reporting an investigation of disinvestment in a local healthcare setting. BMC Health Serv. Res. 2017, 17, 323. [CrossRef] [PubMed]

71. Harris, C.; Garrubba, M.; Allen, K.; King, R.; Kelly, C.; Thiagarajan, M.; Castleman, B.; Ramsey, W.; Farjou, D. Development, implementation and evaluation of an evidence-based program for introduction of new health technologies and clinical practices in a local healthcare setting. BMC Health Serv. Res. 2015, 15, 575. [CrossRef] [PubMed]

72. Harris, C.; Allen, K.; Brooke, V.; Dyer, T.; Waller, C.; King, R.; Ramsey, W.; Mortimer, D. Sustainability in Health care by Allocating Resources Effectively (SHARE) 6: Investigating methods to identify, prioritise, implement and evaluate disinvestment projects in a local healthcare setting. BMC Health Serv. Res. 2017, 17, 370. [CrossRef] [PubMed]

73. Harris, C.; Garrubba, M.; Melder, A.; Voutier, C.; Waller, C.; King, R.; Ramsey, W. Sustainability in Health care by Allocating Resources Effectively (SHARE) 8: Developing, implementing and evaluating an evidence dissemination service in a local healthcare setting. BMC Health Serv. Res. 2018, 18, 151. [CrossRef] [PubMed]

74. Harris, C.; Green, S.; Elshaug, A.G. Sustainability in Health care by Allocating Resources Effectively (SHARE) 10: Operationalising disinvestment in a conceptual framework for resource allocation. BMC Health Serv. Res. 2017, 17, 632. [CrossRef] [PubMed]

75. Harris, C.; Green, S.; Ramsey, W.; Allen, K.; King, R. Sustainability in Health care by Allocating Resources Effectively (SHARE) 9: Conceptualising disinvestment in the local healthcare setting. BMC Health Serv. Res. 2017, 17, 633. [CrossRef]

76. Harris, C.; Allen, K.; Waller, C.; Dyer, T.; Brooke, V.; Garrubba, M.; Melder, A.; Voutier, C.; Gust, A.; Farjou, D. Sustainability in Health care by Allocating Resources Effectively (SHARE) 7: Supporting staff in evidence-based decision-making, implementation and evaluation in a local healthcare setting. BMC Health Serv. Res. 2017, 17, 430. [CrossRef]

77. Harris, C.; Allen, K.; Ramsey, W.; King, R.; Green, S. Sustainability in Health care by Allocating Resources Effectively (SHARE) 11: Reporting outcomes of an evidence-driven approach to disinvestment in a local healthcare setting Milena Pavlova. BMC Health Serv. Res. 2018, 18, 386. [CrossRef]

78. Polisena, J.; Clifford, T.; Elshaug, A.G.; Mitton, C.; Russell, E.; Skidmore, B. Case studies that illustrate disinvestment and resource allocation decision-making processes in health care: A systematic review. Int. J. Technol. Assess. Health Care 2013, 29, 174-184. [CrossRef]

79. Elshaug, A.G.; Watt, A.M.; Mundy, L.; Willis, C.D. Over 150 potentially low-value health care practices: An Australian study. Med. J. Aust. 2012, 197, 556-560. [CrossRef]

80. Elshaug, A.G.; Moss, J.R.; Littlejohns, P.; Karnon, J.; Merlin, T.L.; Hiller, J.E. Identifying existing health care services that do not provide value for money. Med. J. Aust. 2009, 190, 269-273. [CrossRef] [PubMed]

81. Mitton, C.; Donaldson, C. Health care priority setting: Principles, practice and challenges. Cost Eff. Resour. Alloc. 2004, 2, 3. [CrossRef] [PubMed]

82. Harris, C.; Allen, K.; Waller, C.; Brooke, V. Sustainability in health care by allocating resources effectively (SHARE) 3: Examining how resource allocation decisions are made, implemented and evaluated in a local healthcare setting. BMC Health Serv. Res. 2017, 17, 340. [CrossRef] [PubMed]

83. Harris, C.; Allen, K.; King, R.; Ramsey, W.; Kelly, C.; Thiagarajan, M. Sustainability in Health care by Allocating Resources Effectively (SHARE) 2: Identifying opportunities for disinvestment in a local healthcare setting. BMC Health Serv. Res. 2017, 17, 328. [CrossRef] [PubMed] 
84. Harris, C.; Ko, H.; Waller, C.; Sloss, P.; Williams, P. Sustainability in Health care by Allocating Resources Effectively (SHARE) 4: Exploring opportunities and methods for consumer engagement in resource allocation in a local healthcare setting. BMC Health Serv. Res. 2017, 17, 329. [CrossRef] [PubMed]

85. Salem, M.A.; Shawtari, F.A.; Shamsudin, M.F.; Hussain, H.I. The relation between stakeholders' integration and environmental competitiveness. Soc. Responsib. J. 2016, 12, 755-769. [CrossRef]

86. Hussain, M.; Ajmal, M.M.; Gunasekaran, A.; Khan, M. Exploration of social sustainability in healthcare supply chain. J. Clean. Prod. 2018, 203, 977-989. [CrossRef]

87. Lee, Y.-M.; Hu, J.-L. Integrated Approaches for Business Sustainability: The Perspective of Corporate Social Responsibility. Sustainability 2018, 10, 2318. [CrossRef]

88. Ray, S.; Chaudhuri, B.R. Business Group Affiliation and Corporate Sustainability Strategies of Firms: An Investigation of Firms in India. J. Bus. Ethics 2018, 153, 955-976. [CrossRef]

89. Lo, H.-W.; Liou, J.J.H.; Wang, H.-S.; Tsai, Y.-S. An integrated model for solving problems in green supplier selection and order allocation. J. Clean. Prod. 2018, 190, 339-352. [CrossRef]

90. Chen, C.-C.; Shih, H.-S.; Shyur, H.-J.; Wu, K.-S. A business strategy selection of green supply chain management via an analytic network process. Comput. Math. Appl. 2012, 64, 2544-2557. [CrossRef]

91. Piboolsravut, P. Sufficiency Economy. ASEAN Econ. Bull. 2004, 21, 127-134. [CrossRef]

92. Hovlid, E.; Bukve, O.; Haug, K.; Aslaksen, A.B.; Von Plessen, C. Sustainability of healthcare improvement: What can we learn from learning theory? BMC Health Serv. Res. 2012, 12, 235. [CrossRef] [PubMed]

93. Haas, M.; Hall, J.; Viney, R.; Gallego, G. Breaking up is hard to do: Why disinvestment in medical technology is harder than investment. Aust. Health Rev. Publ. Aust. Hosp. Assoc. 2012, 36, 148-152. [CrossRef] [PubMed]

(C) 2019 by the authors. Licensee MDPI, Basel, Switzerland. This article is an open access article distributed under the terms and conditions of the Creative Commons Attribution (CC BY) license (http://creativecommons.org/licenses/by/4.0/). 